\title{
REVIEW
}

\section{Formal education and back pain: a review}

\author{
C E Dionne, M Von Korff, T D Koepsell, R A Deyo, W E Barlow, H Checkoway
}

\begin{abstract}
Objectives-To summarise the scientific evidence on the relation between educational status and measures of the frequency and the consequences of back pain and of the outcomes of interventions among back pain patients, and to outline possible mechanisms that could explain such an association if found.

Design-Sixty four articles published between 1966 and 2000 that documented the association of formal education with back pain were reviewed.
\end{abstract}

Main results-Overall, the current available evidence points indirectly to a stronger association of low education with longer duration and/or higher recurrence of back pain than to an association with onset. The many reports of an association of low education with adverse consequences of back pain also suggest that the course of a back pain episode is less favourable among persons with low educational attainment. Mechanisms that could explain these associations include variations in behavioural and environmental risk factors by educational status, differences in occupational factors, compromised "health stock" among people with low education, differences in access to and utilisation of health services, and adaptation to stress. Although lower education was not associated with the outcomes of interventions in major studies, it is difficult, in light of the current limited available evidence, to draw firm conclusions on this association.

Conclusion-Scientific evidence supports the hypothesis that less well educated people are more likely to be affected by disabling back pain. Further study of this association may help advance our understanding of back pain as well as understanding of the relation between socioeconomic status and disease as a general phenomenon.

(F Epidemiol Community Health 2001;55:455-468)

Low socioeconomic status (SES) is associated with increased mortality and morbidity from many conditions, including musculoskeletal disorders. ${ }^{1-31}$ Examination of this association has improved our understanding of the causes and natural history of some diseases, among which are breast and cervical cancers ${ }^{32}{ }^{33}$ and myocardial infarction. ${ }^{34} 35$

Education is often considered the best surrogate measure of SES, because it is generally easy to collect and is unlikely to be affected by chronic diseases that begin in adult life, as might occupation and income. ${ }^{36}$ It provides us with a quick and useful proxy for a much more complex set of social factors. ${ }^{16711121437}$ Education may also be a marker for specific traits like intelligence, acquisition of adaptive skills, or awareness of risky health behaviours.

Back pain affects $70 \%$ to $80 \%$ of adults at some time during their lives, ${ }^{38}$ and represents an enormous burden for industrial societies. ${ }^{39-45}$ Back problems constitute one of the most common reasons for all physician visits in the United States, ${ }^{46}{ }^{47}$ and a leading cause of disability among adults. ${ }^{39} 48$ Although our knowledge of the causes and the natural history of back pain has benefited from extensive research efforts, it is still rather limited. ${ }^{42}{ }^{48}{ }^{49}$ Assuming that research on back pain might benefit from the investigation of the relation between back problems and SES, we reviewed the scientific evidence linking formal education to back pain, and possible mechanisms that may explain this association.

Education has been considered to play three different parts in relation to back pain: as a predictor of the frequency (incidence, recurrence and prevalence) of back pain, as a predictor of the outcomes of back pain episodes (importance and duration of pain and disability, interference with work and other activities, and health care consumption), and as a predictor of the outcomes of surgical and rehabilitative interventions performed among series of back pain patients.

\section{Methods}

SELECTION OF ARTICLES

Articles documenting the association of formal education with back pain that were published between January 1966 and June 2000, were identified through a search on the 1988-2000 Embase, 1966-1999 ERIC and 1966-2000 Medline databases, and reviewed. The search strategy included "back pain or backache" and "educational status or formal education". Because formal education is often not mentioned in articles' titles, key words or abstracts, several papers were identified through a broader search of epidemiological studies on 
back pain, especially those that have investigated psychosocial and socioeconomic factors.

QUALITY ISSUES

Each article was rated according to the following quality criteria with regards to the assessment of the formal education-back pain association: (1) selection of participants, (2) sample size ( $\geq 300$ ), (3) measure of education, (4) length of follow up ( $\geq 3$ months), (5) drop out rate $(<40 \%)$, (6) measure of outcome, (7) multivariate analysis, (8) point estimates and (9) consideration of effect modification by gender. The last four criteria were assessed for each outcome measured in a study. Criteria were broadly applied, and designated "acceptable" or "not acceptable". When the information was insufficient to make a clear judgement, the criteria were designated "not acceptable". Studies with less than four "not acceptable" scores were labelled "major study" and used for interpretation. Studies with four or more "not acceptable" scores were labelled "other study".

\section{Results}

EDUCATION AND THE INCIDENCE, RECURRENCE AND PREVALENCE OF BACK PAIN

Table 1 summarises 19 major studies that have examined the association between education and measures of back pain frequency in 23 instances. In 19 instances reported in 16 studies, low educational status was significantly associated with increased prevalence of back pain. ${ }^{411} 18293650-60$ Only four major studies found no significant association of formal education with the frequency of back pain..$^{5861-63}$ There was no apparent pattern of similarity among the negative studies by design, country nor outcome measure. However, three of the four negative studies had sample sizes among the four smallest of all major studies $(n=238$ to 481 compared with 1135 to 84572$) \cdot{ }^{61-63}$ The other negative report was that of Hurwitz and Morgenstern (1997), who, with the largest sample size of all major studies $(n=84572)$, found a significant association between low education and two week period prevalence of disabling back pain but no association with the two week prevalence of non-disabling back pain (no back related restricted activity days)..$^{58}$ Only one study with a small sample size $(n=154)$ found an association between low education and a higher frequency of back pain, but it was significant only among women. ${ }^{18}$ These observations have two implications: (1) given that the association of education with back pain frequency is often observed in large population surveys, one might argue that it is an artefact created by the very high statistical power of these studies. Although this could be true in some instances, this position is challenged by the fact that one small study found the association to be significant and that a quite large survey did not; (2) there seems to be some important differences according to the outcome measures used, although back pain is defined so heterogeneously across studies that it is very difficult to draw consistent lines. As there might be very important differences between various forms of back pain beyond the strict duration of symptoms ${ }^{64}$ it is possible that education is associated only with the most severe forms of back pain, but that revealing this relation requires higher statistical power. Thus, it seems possible that heterogeneity in results across studies comes in part from a combination of differences in outcome measures (more or less stringent definitions) and variation in statistical power.

In the only major incidence study, a report on 271 subjects without any prior history of back pain from a probability sample of a large Washington State HMO's enrollees, the odds ratios comparing back pain incidence among subjects with some college and college graduates and subjects with high school or less were 0.59 and 1.01 respectively, both statistically non-significant. ${ }^{61}$

In positive major studies, although the strength of the association or the differences are sometimes relatively small, the point estimates are generally adjusted for several variables that often include other measures of SES like occupation and income and other variables that could be intermediate between education and outcomes. Such overadjustment would usually bias results toward the null (that is, toward finding no association), ${ }^{72}$ as would also do random misclassification of education, as it has been demonstrated that most people tend to exaggerate the amount of schooling they have obtained. ${ }^{73}$ The association between low education and the frequency of back pain observed in most major studies thus seems to be quite robust.

The majority of studies reviewed were cross sectional and examined self reported point, period or lifetime prevalence of back pain. As amount of formal schooling rarely changes after age $20-25$ and disabling back pain typically begins after that age, there is probably no important problems with regard to temporal sequence in making cross sectional comparisons. Relying on self reported prevalence of back pain leads to two main concerns: firstly, the association of education with back pain frequency is potentially confounded with differences in recall and reporting of back symptoms across education groups. Prior research using physician validated outcomes suggests this is not an important source of bias. For instance, in the study of Cunningham and Kelsey (1984) low education was found to be associated with higher point prevalence of signs and symptoms of back pain, in agreement with most other prevalence studies that used self report of back pain. ${ }^{4}$ Secondly, as for chronic episodic diseases prevalence is approximately (incidence) $\times$ (average episode duration) $\times$ (average number of episodes), ${ }^{74}$ the association of formal education with back pain prevalence could reflect an effect of education on back pain onset rates, duration, or number of back pain episodes or some combination of them. Using period prevalence of back pain constitutes a particular problem, because this measure fails to distinguish between incident and prevalent cases. No major studies have looked specifically at the 


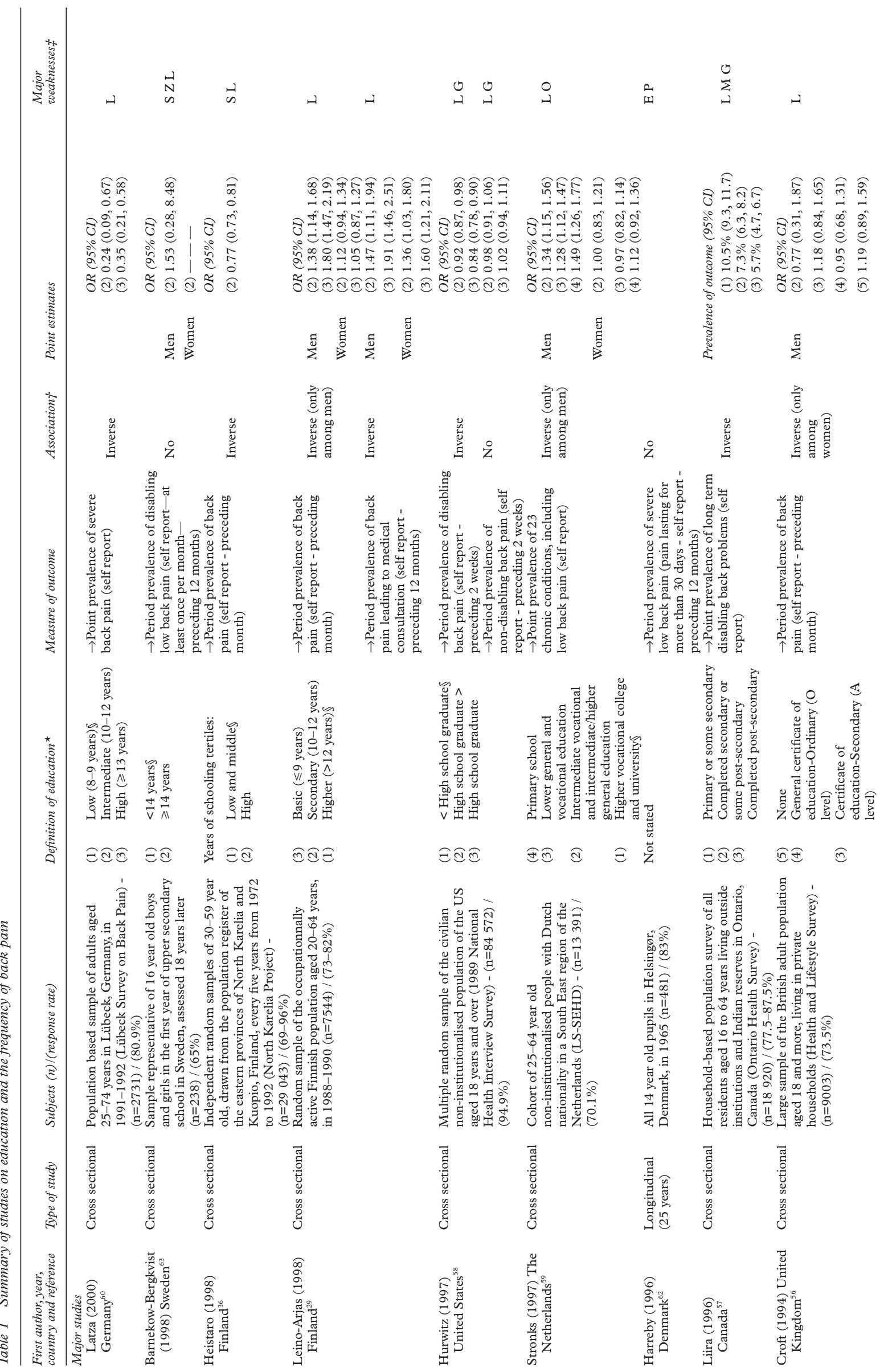




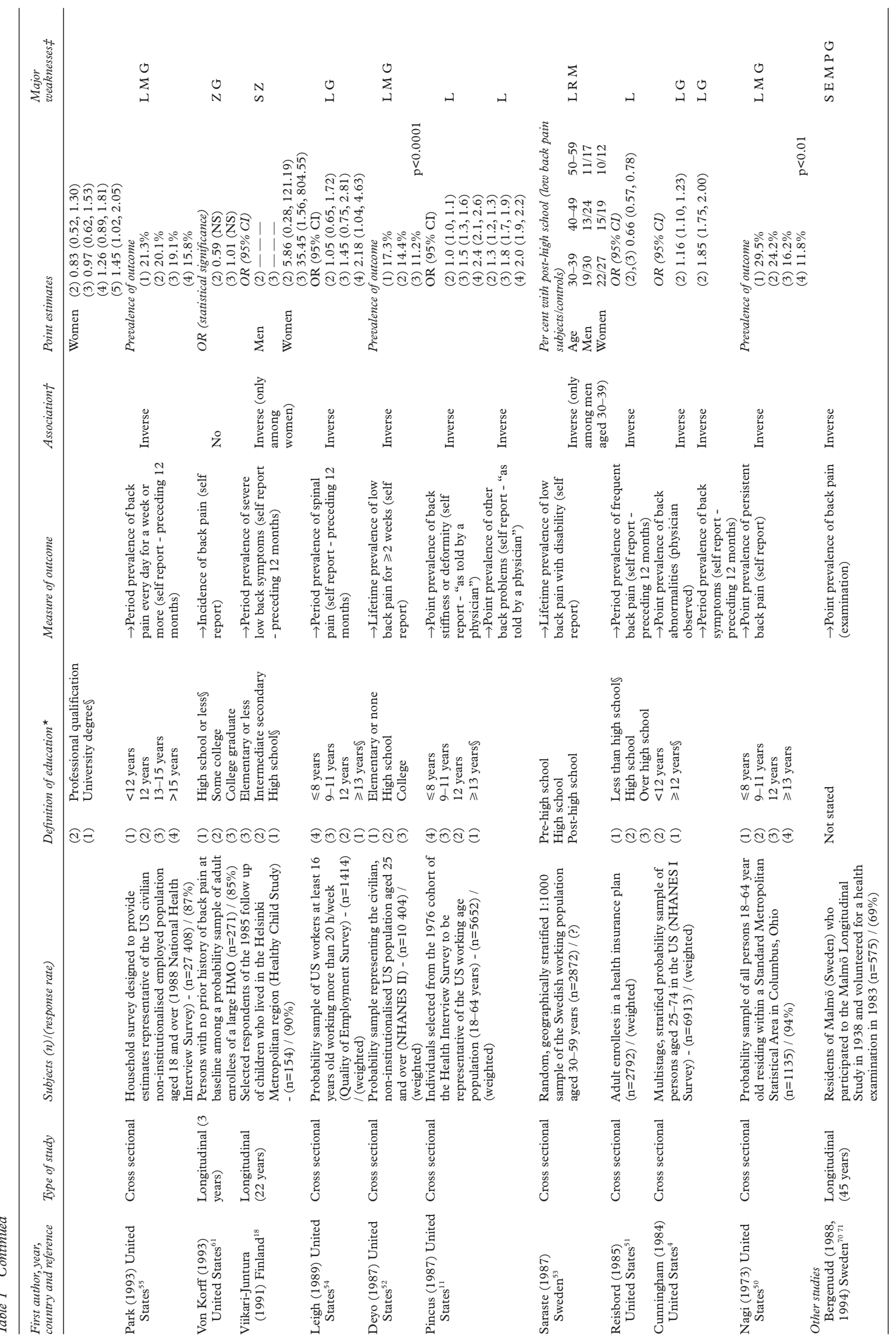




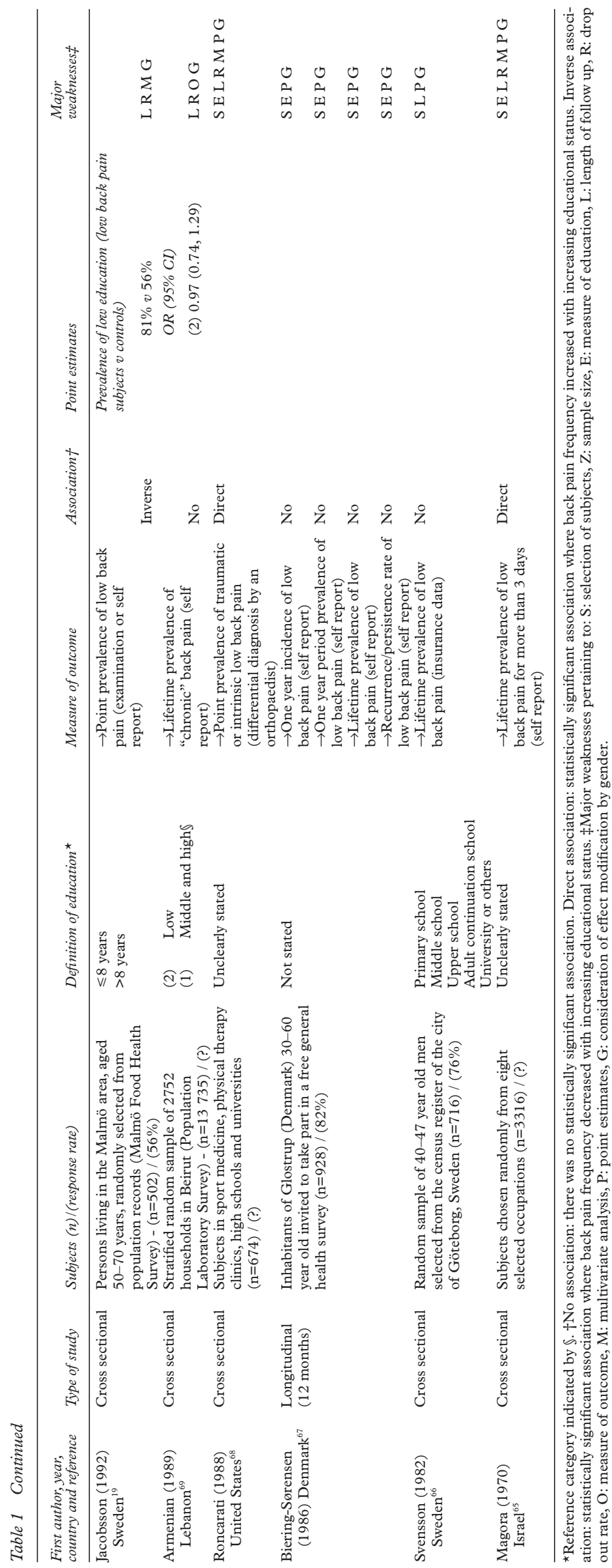

association of education with the recurrence of back pain.

Overall, the current limited available evidence points indirectly to a stronger effect of education on the duration and/or recurrence of back pain than to an association with onset.

EDUCATION AND THE OUTCOMES OF BACK PAIN EPISODES

Studies of education as a predictor of the outcomes of back pain episodes are summarised in table 2. In 20 instances reported in the 11 major studies, worse outcomes were associated significantly with low education. ${ }^{48}{ }^{75-83}$ Negative results were found in only five instances, reported in two studies. ${ }^{76}$ No major studies reported worse outcomes among better educated subjects. The validity of comparing study results is impaired by the heterogeneity of the methods used, including the choice of subjects and the definition of back pain and outcome measures. The following examples illustrate this diversity and the many methodological issues to consider in interpreting their findings.

Badley and Ibañez (1994) used data from the 1986 Canada Health and Activity Limitation Survey (HALS), which included 132337 non-institutionalised persons aged 16 years and older. ${ }^{81}$ More than half of this sample $(54 \%)$ had some limitation of activity, 8228 from back pain (in neck or back). The authors found an independent association of low education with activity limitation attributable to back pain ( $\leq$ grade 8 versus $>$ secondary education: $\mathrm{OR}=1.25,95 \%$ confidence intervals: $1.11,1.40)$. This study used a crude index of disability (a "yes/no" answer to a single question). It had an extremely large sample size that might have caused most associations to be statistically significant.

In a three month longitudinal study of 179 patients presenting with low back pain (pain below T12) to the outpatient clinic of a hospital, ${ }^{76}$ seeking compensation decreased and self rated pain improvement increased with increasing education. No association was found with days of pain, improvement in disability, employment status and the number of visits made to a physician. Education was, however, also strongly associated with the language used by the study subjects (English versus Spanish), which predicted disability in multivariate analyses. Although some findings of this study were replicated using NHANES II survey data, the population under study was largely indigent and Hispanic and not representative of the US population, which may explain why some of the dependent variables were not significantly associated with education.

In a 22 year longitudinal study of 391 male employees of a Swedish company, the longest longitudinal study by far, Åstrand and Isacsson (1988) did not find education to be predictive of early retirement with a back diagnosis (disorders in thoracic or lumbar areas). However, they identified a protective effect of education manifested by a relative risk of early retirement for all diagnoses of $0.8(\mathrm{p}=0.004)$ for each additional year of education. There were few cases of early retirement for back pain 


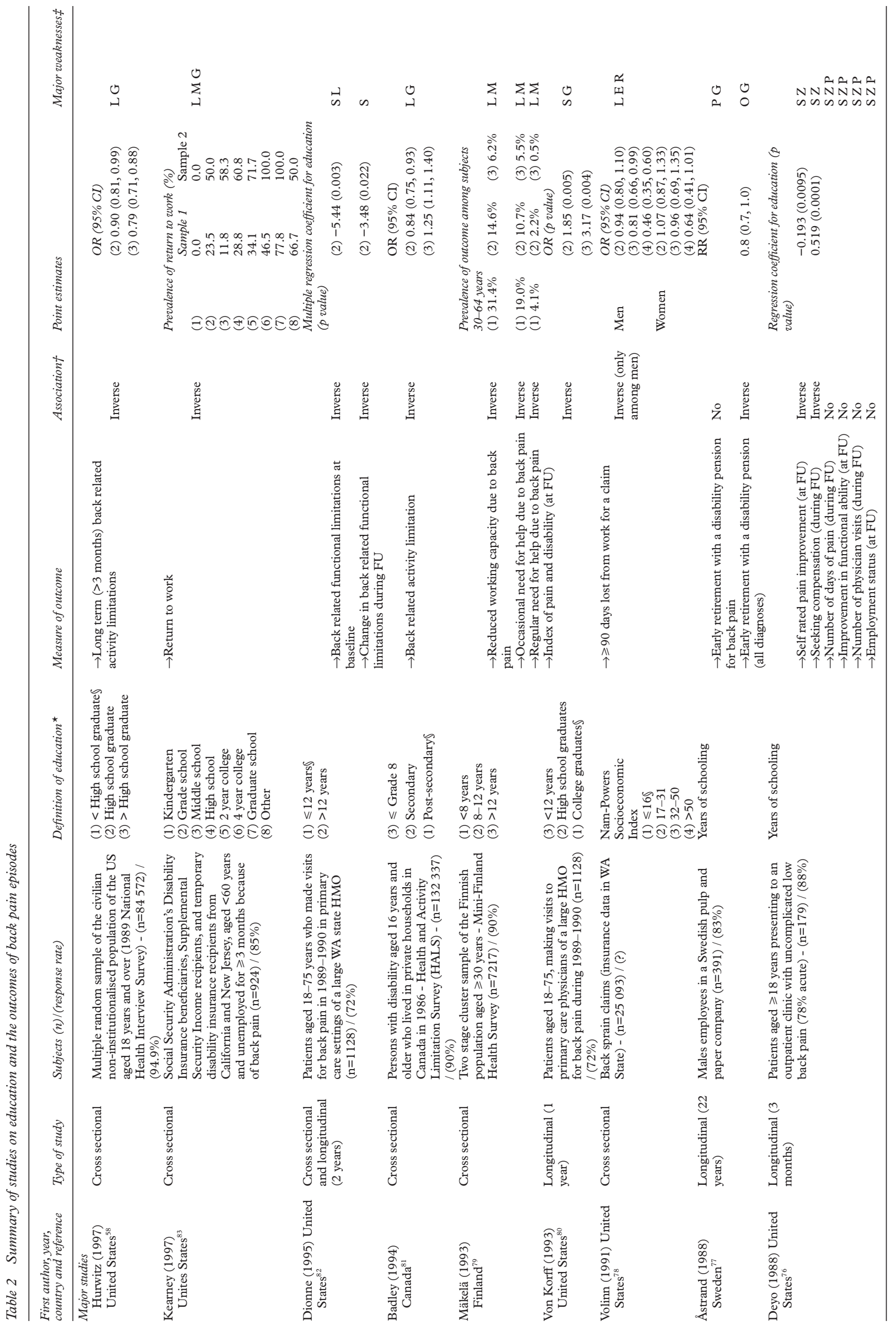




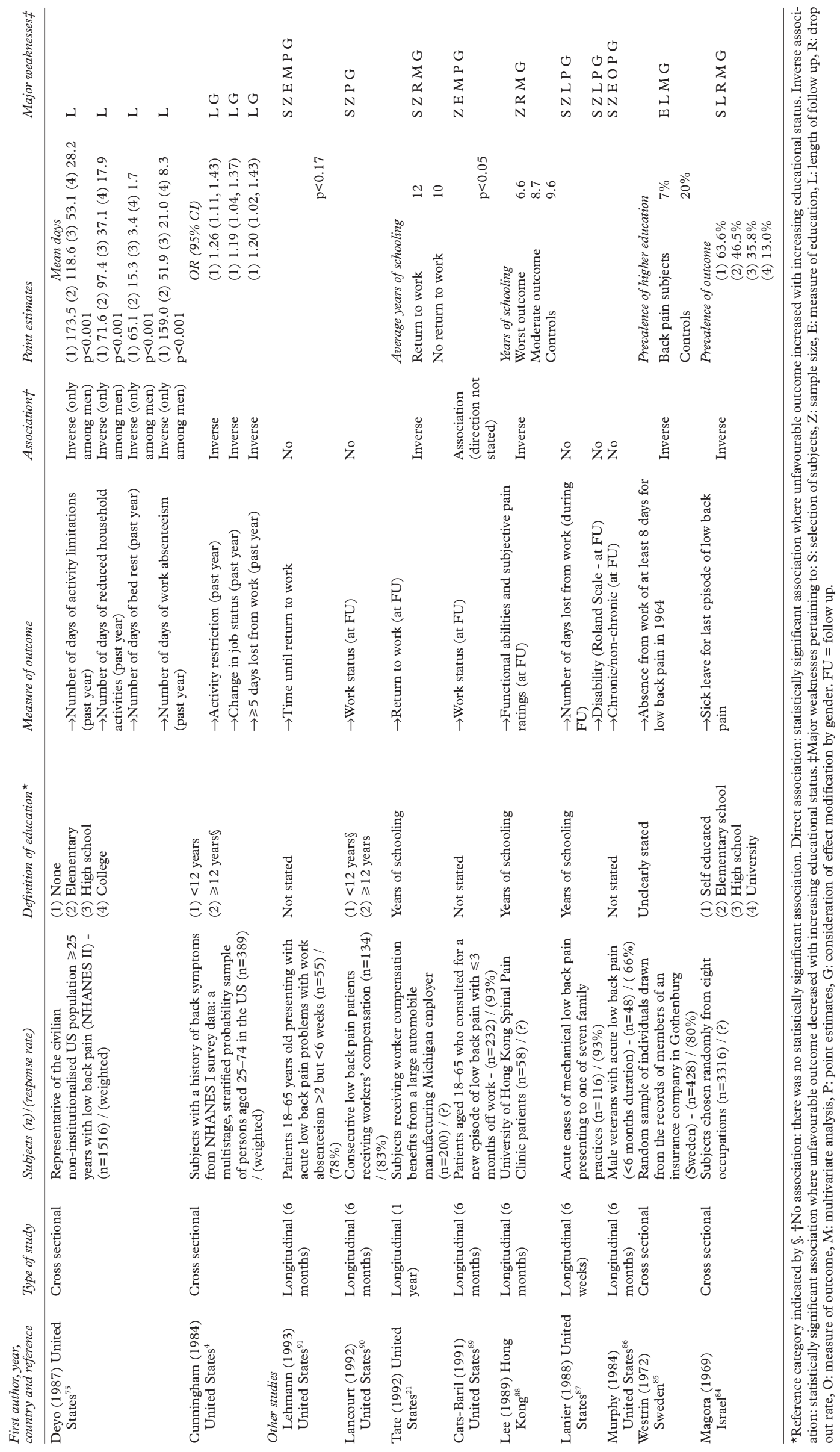


in this study, which also had the disadvantage of including only blue collar workers with very similar educational backgrounds, making it difficult to contrast differences between education groups. ${ }^{77}$

In one study that aimed specifically at explaining the association between education and the consequences of back pain, 1213 HMO enrollees who consulted a primary care physician for back pain in 1989-1990, were followed up for two years. Low education was associated cross sectionally and longitudinally with back related functional limitations measured with a modified version of the Roland-Morris scale. The statistical associations were explained mostly by combinations of psychological (symptoms of somatisation and depression, patient's expectation of continuous pain), behavioural (cigarette smoking, body mass index) and occupational (handling, kneeling and job strength) factors. ${ }^{82}$ These results have not been replicated yet.

The many reports of a relation of low education with adverse consequences of back pain, even after multivariate adjustment for several variables, suggest that the course of a back pain episode is less favourable among persons with low educational attainment.

EDUCATION AND THE OUTCOMES OF

INTERVENTIONS AMONG BACK PAIN PATIENTS

Synthesising the results of studies on the third role of education is much less straightforward. Only two studies among 17 (table 3) met our definition of major studies and both concluded to no association between formal education and outcomes. ${ }^{92} 93$ Other studies found very heterogeneous results. As the study objectives, populations, interventions, outcome measures, statistical techniques, length of follow up and the way education was considered are very different from one study to another, it is particularly difficult to draw firm conclusions from these results.

At this stage of the natural history of the disease, a reduction in the variability of educational attainment could be advanced as a possible difficulty in detecting a difference on outcomes between groups. If less educated people get more episodes of back pain and are also more likely to shift towards chronicity than people with higher level of education, theoretically there must be relatively few people in the highest groups of educational attainment among severe cases, making less easy to contrast differences between groups of education. This seems to be true in several "other" studies where the baseline educational status of subjects was sufficiently described. ${ }^{94} 97100101$ 103-105

Thus, although the limited evidence for an association of educational status with the outcomes of surgical and rehabilitative interventions among back pain patients is negative, this role of education could not be denied yet and needs more research efforts to be understood.
KEY POINTS

- The association between low education and higher frequency of back pain seems to be robust.

- The course of a back pain episode seems less favourable among those with lower education.

- That many health related events are linked to education suggests that low SES increases susceptibility or impairs adaptation to illness.

- Studies on back pain should include formal education as a risk factor of its own.

- Adjusting for education could lead to underestimate the association between variables education is associated with and back pain outcomes.

POSSIBLE UNDERLYING MECHANISMS

The fact that many health related events are linked to formal education suggests that something about low SES or other specific traits linked to education increases susceptibility or impairs adaptation to illness. Five hypotheses that could explain this association are outlined below and explored in the context of back pain. These hypotheses are not mutually exclusive.

Behavioural and environmental risk factors Persons in lower socioeconomic groups are more likely to live in a toxic, hazardous and non-hygienic environment, resulting in a broad array of disease concerns. ${ }^{1{ }^{14} 73}$ Besides benefiting from better living conditions, people in the highest groups of education are also more likely to be aware of risks and to adjust their behaviours accordingly. ${ }^{37}$ Strong evidence exists for the impact on health of cigarette smoking, obesity, alcohol consumption, substance misuse, life changes, chronic stressful events, social support and dietary habits, among others. These factors are often linked with education, ${ }^{9} 203037111-114$ and there is some evidence for their adverse effects on the back. ${ }^{19} 5354$ 87 115-118 For instance, cigarette smoking has been postulated to act on back pain by way of impaired fibrinolysis and reduced nutrition to intervertebral discs, induction of osteoporosis, and mechanical stress to the spine from increased abdominal pressure provoked by coughing. ${ }^{116}{ }^{119}$ Obesity is considered to affect the spine by conferring mechanical disadvantages. ${ }^{120}$ Given the current state of knowledge, however, it is difficult to propose any particular combination of these risk factors as a sufficient explanation for the association of education with back pain.

The mechanisms linking psychological factors to back pain are still obscure; anxious or depressed patients may have greater awareness of pain or they may have more difficulty coping with it and consult health care providers earlier. Life stress could also be a precursor of back pain and act directly by an unknown mechanism. ${ }^{115} 117121$ The work of Pincus and Callahan, who noticed that low formal education was consistently associated with increased 


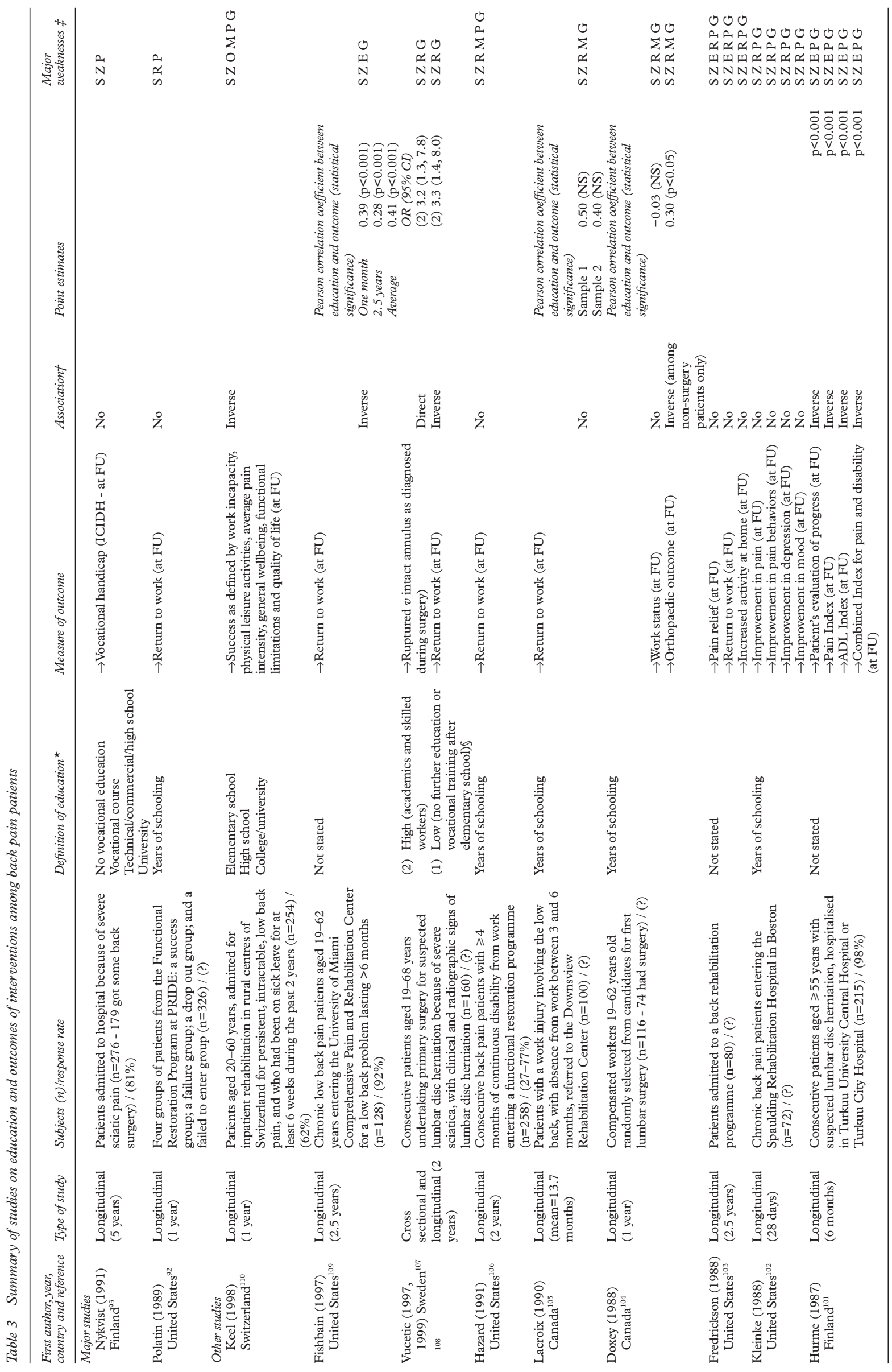




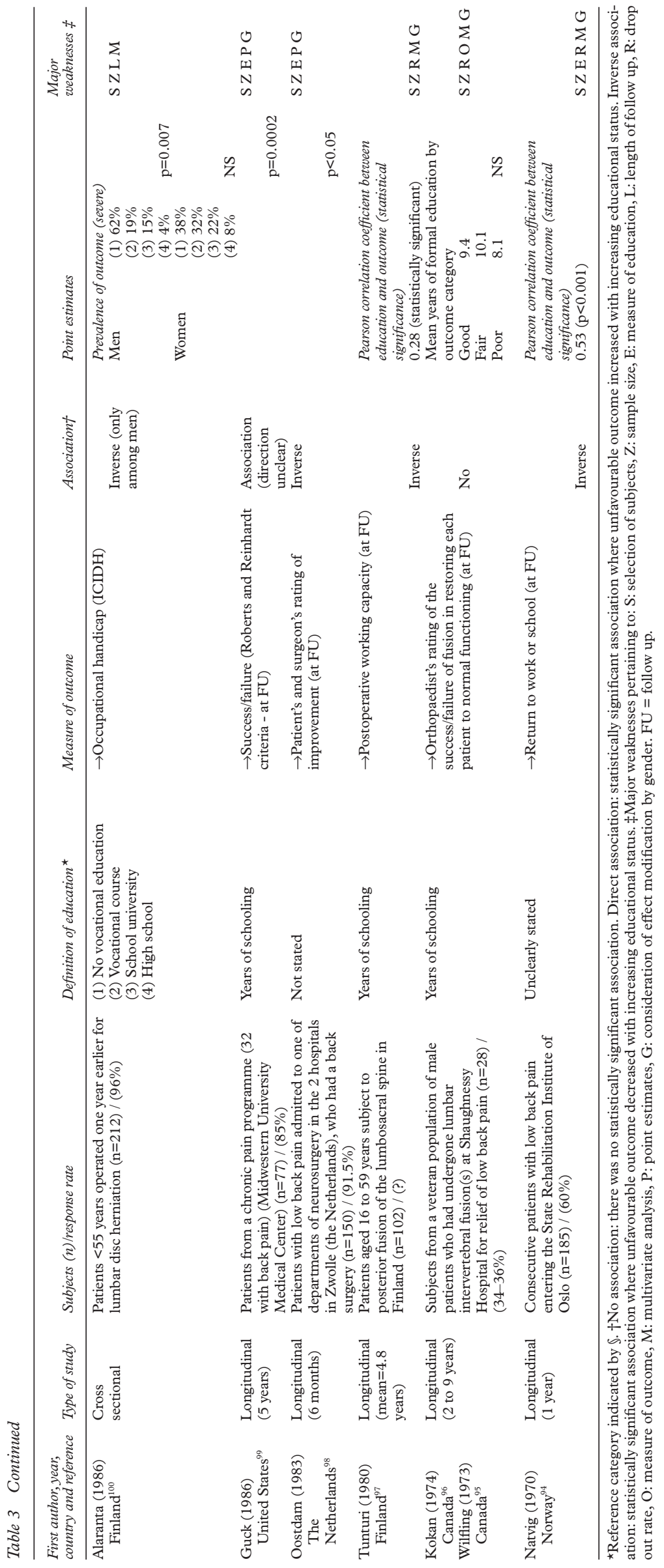

morbidity and mortality in rheumatoid arthritis, has lead to identify other important psychological variables (helplessness and hostility) that might become the focus of future interventions. ${ }^{6} 712$ 122-126

\section{Occupational factors}

It is widely believed that a hazardous work environment and physically demanding jobs play an important part in the aetiology of back pain. ${ }^{6584} 127128$ People with low education and low paying jobs are more likely to work in physically demanding jobs and tasks involving stresses on the spine. After an episode of back pain, they may have to wait longer to resume a demanding job than persons with sedentary occupations. ${ }^{4} 82041497584129130$ They may be less satisfied with their jobs and less motivated to continue working or to work as hard after an episode of back pain. ${ }^{5}{ }^{76}$ Conversely, persons with low education may have poorer sick leave benefits or fear loss of their jobs because of back pain, and be more prone to return to a physically demanding job before the back injury has resolved, risking reinjury or prolongation of symptoms..$^{51}$ This explanation was not sufficient, however, to account for differences in outcomes across educational groups in several studies. $^{118196075100131}$ For instance, Leigh and Sheetz (1989) found a significant association between back pain period prevalence and low education even after adjustment for other risk factors, including occupation, physical demands and repetitiveness of work. ${ }^{54}$ Although these results suggest that occupational factors alone are not sufficient to explain the association, the findings may have resulted from imperfect classification of occupation and physical demands of the job, as these are difficult to measure and classify. ${ }^{132}$

\section{Compromised "health stock"}

In the perspective of Grossman's application of consumer theory to health care, a person's health is viewed as capital ("health stock") that is inherited and reduced by depreciation (biological aging) and finally by death, when the capital falls below a certain minimal level. ${ }^{133}$ There is some evidence that socioeconomic circumstances during childhood may influence adult health by compromising this "health stock" at the beginning of adult life. ${ }^{20}$ This hypothesis is compatible with the "pain prone disorder" suggested in the literature on back pain. ${ }^{134}$ In a study on premorbid social adjustment of chronic back pain sufferers, the subjects were found to have limited formal education. ${ }^{135}$ "Most had experienced unmet dependency needs... and many had familial models for pain and disability present in their early life experience". The study of Porter and Oakshot, ${ }^{136}$ who observed a higher prevalence of small adult vertebral canal among subjects with lower education (as a marker of early impairment of growth) also supports this hypothesis. 
Health services access and utilisation

Differential access to or use of health services across groups of education, or differences in the benefits obtained from the use of health care are other possible explanations to account for the relation between education and health. ${ }^{141214{ }^{24}}$ People of lower SES do less well in the health care system, although the reasons for this are unknown. ${ }^{24}$ One hypothesis is that low education would impair communication and trust with health professionals, and make it more difficult to use services effectively. ${ }^{24}$ For back pain, it is possible that patients with lower education have less access to some specialised interventions, wait longer before consulting or have lower compliance with health professionals' recommendations. However, several reports found that people with back pain in low education groups more often consulted a physician and were more frequently hospitalised. ${ }^{19203750}$ In a national US survey, the relation between education and duration of back related disability was unexplained by medical care utilisation. There was a significant trend toward more frequent hospitalisation among those with less education. The proportion of subjects who had sought medical care or had undergone back surgery was similar in each educational group. ${ }^{75}$ These results are in agreement with the conclusion of a recent paper by Pincus et al (1998) on access to care as a determinant of health, in which the authors demonstrate, on the basis of many international studies (several of them from countries with longstanding universal access to medical care), that widening disparities in health according to SES are not explained mainly by access to care. ${ }^{137}$ The association between education and back pain thus seems unlikely to be explained by differences in the use of health services. ${ }^{111} 14192081122$

\section{Adaptation to stressful events}

There is evidence for the joint effect of stressful events and an altered social environment as an explanation for the relation between SES and health. $^{24141984138}$ Such an effect would be explained as an opportunity for pathogenic agents (stressful events) to affect health when host resistance is lowered by way of endocrine or immunological changes. There are two major circumstances in which the social environment might impair host resistance: (1) when the person is unprepared to function in their social setting and fails to receive adequate feedback that their problem solving efforts are effective and (2) when there is a deficiency in the social support provided by the primary group. This mechanism is supported by studies on animals. ${ }^{139}$ In humans, this hypothesis may explain the increased risk of mortality from myocardial infarction among men with low educational achievement. Men who are socially isolated and experience important changes in their life are more likely to die than others. ${ }^{34} 35$ In view of the current dominant theory of pain $^{140}$ such an effect may operate on back pain by influencing the central mechanisms that modulate the transmission of nociceptive messages to the brain, facilitating pain that persists after the original injury, leading to chronicity. Obesity, cigarette smoking, alcoholism, type A behaviour and neurotic diseases may all be considered as responses to stress. ${ }^{1}$ This hypothesis, tested in only one back pain study to date, has not been supported. ${ }^{82}$

Recently, Kubzansky et al (1999) found a strong association between education and allostatic load, a measure of biological risk across several systems, that was explained by a measure of "hostility", a broad concept associated with "a tendency to devalue the worth and motives of others, to expect that others are likely to be doing wrong, to view one's self as being in opposite toward others, and to desire to inflict harm or see others harmed". Hostility would develop as a response pattern to difficult life circumstances. ${ }^{141}$ The authors concluded that lower levels of education and greater hostility are associated with greater "wear and tear" on the body and that the relation between education and allostatic load may be mediated by hostility. This mechanism needs to be studied further.

\section{SUGGESTIONS FOR FUTURE RESEARCH}

Frequent methodological problems that affected the results of studies reviewed for this paper include: reliance on cross sectional study design and prevalence of outcomes; inconsistency in defining "back pain", education, interventions, outcome measures and length of follow up; selection bias; limited variability in educational status, making it difficult to find differences between groups based on educational status; and low statistical power because of a small number of outcome events. The diversity of the populations studied may also have contributed to variation in results. Many studies limited their analyses to bivariate relations, while others used multivariate models.

As back pain investigators are still looking for strong and modifiable risk factors, many studies examine as many variables as possible. Although such "fishing expeditions" are necessary as a first step toward the identification of major risk factors, hypothesis testing research must focus on a limited number of variables and develop further knowledge of their impact on the disease. Education is a good candidate for this purpose. Studies on back pain should include it as a risk factor on its own. Measuring education as a continuous variable (years of schooling) should be preferred to categorical classifications, and a clear description of the way it is considered in the analyses should be provided. Multivariate analysis methods allowing adjustment for confounding factors should be used to extend bivariate and correlation analyses. Reporting statistical power or confidence limits in studies that did not find statistically significant associations would also be helpful. Determining if education is related to both incidence/recurrence of back pain (or back related disability) and duration of episodes would certainly be an important contribution to the field. Clarifying the role of sex as an effect modifier would also be valuable, as the literature is very inconsistent on this point. 
Few reports among the 64 reviewed for this paper were developed specifically to examine the relation of sociodemographic variables with the outcomes. More research efforts geared toward testing specific hypotheses are needed. Prospective studies on subjects with no prior history of back pain seems to be the most promising study design to this end, and a sine qua non condition to answer some questions, particularly those dealing with the directionality of associations.

Another key question concerns exposure measurement; many suspected risk factors are complicated constructs that require care in their measurement, a need more likely to be met in prospective studies. This is certainly the case for psychological factors and job requirements. Studies of the effect of interactions between stress and coping strategies are also needed. Heterogeneity in the definition of study subjects, back pain, interventions, outcomes and length of follow up was a constant concern during our review. Although it is difficult to reach a consensus to define these parameters, the field would certainly benefit from a restriction to some commonly used definitions.

The association between education and back pain has an important immediate implication: adjusting for educational status in multivariate analyses could lead to underestimation of the association between some independent variable education is associated with (for instance, cigarette smoking) and back pain outcomes. It thus seems advisable to compare results obtained with and without adjustment on educational status in aetiological research on back pain.

\section{Conclusion}

Scientific evidence supports the hypothesis that less well educated people are more likely to be affected by disabling back pain. However, the evidence is stronger for an effect of education on the duration and/or recurrence of back pain episodes than for an effect of education on the incidence of back pain. Educational status may be a "marker" for other factors involved in the aetiology or natural history of the disease, acting as a proxy for SES. Back pain is still an enormous public health problem in all Western societies. ${ }^{44}{ }^{48}$ Despite extensive research work, our understanding of the aetiology and natural history of this condition is still very limited. While the contribution of some risk factors has been highlighted, the search toward the development of a model that accounts for occupational, sociodemographic, biological and psychological characteristics must be pursued. Few traits have demonstrated as a strong and consistent association with back pain as education. It may well be a pathway to a better understanding of this illness and certainly deserves scientific attention.

Funding: this work was supported in part by the National Health Research and Development Program of Canada (NHRDP) and the Quebec Health Research Funds (FRSQ) through scholarships to CE Dionne.

Conflicts of interest: none.
1 Syme SL, Berkman LF. Social class, susceptibility and sickness. Am f Epidemiol 1976;104:1-8.

2 Jenkins CD. Low education: a risk factor for death. $N$ Engl $f$ Med 1978;299:95-6.

3 Zant JL, Dekker-Saeys AJ, Van Den Burg IC, et al. Sthenia, ambition and educational level in patients suffering from ankylosing spondylitis: a controlled study of personality features as compared to rheumatoid arthritis and unspecified low back pain. Clin Rheumatol 1982;1:243-50.

4 Cunningham LS, Kelsey JL. Epidemiology of musculoskeletal impairments and associated disability. Am $\mathcal{F}$ Public Health 1984;74:574-9.

5 Leigh JP. An empirical analysis of self-reported, worklimiting disability. Med Care 1985;23:310-19.

6 Pincus T, Callaghan LF. Formal education as a marker for increased mortality and morbidity in rheumatoid arthritis. fChron Dis 1985;38:973-84.

7 Pincus T, Callahan LF. Taking mortality in rheumatoid arthritis seriously - predictive markers, socioeconomic staarthritis seriously-predictive markers, socioecon

8 Marmot MG, McDowall ME. Mortality decline and widening social inequalities. Lancet 1986;ii:274-6.

$9 \mathrm{La}$ Vecchia C, Negri E, Pagano R, et al. Education, prevalence of disease, and frequency of health care utilization. $\mathcal{F}$ Epidemiol Community Health 1987;41:161-5.

10 Nosek MA, Parker RM, Larsen S. Psychosocial independence and functional abilities: their relationship in adults with severe musculoskeletal impairment. Arch Phys Med Rehabil 1987;68:840-5.

11 Pincus T, Callaghan LF, Burkhauser RV. Most chronic diseases are reported more frequently by individuals with fewer than 12 years of formal education in the age 18-64 United States population. F Chron Dis 1987;40:865-74.

12 Callahan L, Pincus T. Formal education level as a significant marker of clinical status in rheumatoid arthritis. Arthritis Rheum 1988;31:1346-57.

13 Mitchell JM, Burkhauser RV, Pincus T. The importance of age, education, and comorbidity in the substantial earnings osses of individuals with symmetric polyarthritis. Arthritis Rheum 1988;31:348-57.

14 Pincus T. Formal educational level-a marker for the importance of behavioral variables in the pathogenesis, morbidity, and mortality of most diseases? I Rheumatol 1988;15:1457-60.

15 Mäkelä M, Heliövaara M. Prevalence of primary fibromyalgia in the Finnish population. BMF 1991;303:216-19.

16 Mäkelä M, Heliövaara M, Sievers K, et al. Prevalence, determinants, and consequences of chronic neck pain in Finland. Am J Epidemiol 1991;134:1356-67.

17 McMahon LF, McLaughlin CG, Petroni GR, et al. Small area analysis of hospital discharge for musculoskeletal diseases in Michigan: the influence of socioeconomic factors. Am $\mathcal{F}$ Med 1991;91:173-8.

18 Viikari-Juntura E, Vuori J, Silverstein BA, et al. A life-long prospective study on the role of psychosocial factors in
neck-shoulder and low-back pain. Spine 1991;16:1056-61.

19 Jacobsson L, Lindgärde F, Manthorpe R, et al. Effect of education, occupational and some lifestyle factors on common rheumatic complaints in a Swedish group aged 50-70 years. Ann Rheum Dis 1992;51:835-43.

20 Mackenbach JP. Socio-economic health differences in the Netherlands: a review of recent empirical findings. Soc Sci Med 1992;34:213-26.

21 Tate DG. Worker's disability and return to work. Am f Phys Med Rehabil 1992;71:92-6.

22 Tsoi WF, Kua EH. Predicting the outcome of schizophrenia ten years later. Aust N Z F Psychiatry 1992;26:257-61.

23 Walsh K, Cruddas M, Coggon D. Low back pain in eight Walsh K, Crudas M, Coggon D. Low back pain in eight
areas of Britain. 7 Epidemiol Community Health 1992;46: areas of $227-30$.

24 Feinstein JS. The relationship between socioeconomic status and health: a review of the literature. Milbank $Q$ 1993;71:279-322

25 Hubert HB, Bloch DA, Fries JF. Risk factors for physical disability in a aging cohort: the NHANES I epidemiologic follow-up study. $\mathcal{F}$ Rheumatol 1993;20:480-8.

26 Katzman R. Education and the prevalence of dementia and Alzheimer's disease. Neurology 1993;43:13-20.

27 Pappas G, Queen S, Hadden W, et al. The increasing disparity in mortality between socioeconomic groups in the United-States, 1960 and 1986. N Engl F Med 1993;329:
103-9.

8 Papageorgiou AC, Mcfarlane GJ, Thomas E, et al. Psychosocial factors in the workplace - do they predict new episodes of low back pain? Evidence from the South Manepisodes of low back pain? Evidence from the Sou
chester Back Pain Study. Spine 1997;22:1137-42.

29 Leino-Arjas P, Hanninen K, Puska P. Socioeconomic variation in back and joint pain in Finland. Eur f Epidemiol tion in back an

30 Lantz PM, House JS, Lepkowski JM, et al. Socioeconomic factors, health behaviors and mortality: results from a nationally representative prospective study of US adults. fAMA 1998;279:1703-8

31 Nilsson PM, Johansson SE, Sundquist J. Low educational status is a risk factor for mortality among diabetic people. Diabet Med 1998;15:213-19.

32 Cohart EM. Socioeconomic distribution of cancer of the female sex organs in New Haven. Cancer 1955;8:34-41.

33 Heck KE, Pamuk ER. Explaining the relation between education and postmenopausal breast cancer. Am ₹ Epidemiol

34 Weinblatt E, Ruberman W, Goldberg JD, et al. Relation of education to sudden death after myocardial infarction. $N$ Engl F Med 1978;299:60-5. 
35 Ruberman W, Weinblatt E, Goldberg JD, et al. Psychosocial influences on mortality after myocardial infarction. Ner Engl F Med 1984;311:552-9.

36 Heistaro S, Vartiainen E, Heliövaara M, et al. Trends of back pain in eastern Finland, 1972-1992, in relation to socioeconomic status and behavioral risk factors. Am F Epidemiol 1998;148:671-82.

37 Franks P, Boisseau V. Educational status and health. $f$ Fam Pract 1980;10:1029-34.

38 Frymoyer J. Back pain and sciatica. N Engl f Med 1988;318: 291-300.

39 Kelsey JL, White AA. Epidemiology and impact of low-back pain. Spine 1980;5:133-42.

40 Spengler DM, Bigos SJ, Martin NA, et al. Back injuries in industry: a retrospective study. I. Overview and cost analysis. Spine 1986;11:241-5.

41 deGirolamo G. Epidemiology and social costs of low back pain and fibromyalgia. Clin f Pain 1991;7:S1-7.

42 Deyo RA, Cherkin D, Conrad D, et al. Cost, controversy, crisis: low back pain and the health of the public. Ann Rev Pub Health 1991;12:141-56.

43 Garg A, Moore JS. Epidemiology of low-back pain in industry. Occup Med 1992;7:593-608.

44 Waddell G. Simple low back pain: rest or active exercise? Ann Rheum Dis 1993;52:317-19.

45 Dionne CE. Low back pain. In: Crombie IK, Croft PR, Linton SJ, et al, eds. Epidemiology of pain. Seattle: IASP Press, 1999.

46 Cypress BK. Characteristics of physician visits for back symptoms: a national perspective. Am f Public Health 1983;73:389-95.

47 Hart LG, Deyo RA, Cherkin DC. Physician office visits for low back pain: frequency, clinical evaluation, and treatment patterns from a U.S national survey. Spine 1995;20:11-19.

48 Waddell $\mathrm{G}$. The back pain revolution. Edinburgh: Churchill Livingstone, 1998.

49 Skovron ML. Epidemiology of low back pain. Baillieres Clin

50 Nagi SZ, Riley LE, Newby LG. A social epidemiology of back pain in a general population. $\mathcal{F}$ Chron Dis $1973 ; 26$ : 769-79.

51 Reisbord LS, Greenland S. Factors associated with self-reported back-pain prevalence: a population-based study. F Chron Dis 1985;38:691-702.

52 Deyo RA, Tsui-Wu YJ. Descriptive epidemiology of low-back pain and its related medical care in the United States. Spine 1987;12:264-8.

53 Saraste H, Hultman G. Life conditions of persons with and without low-back pain. Scand 7 Rehab Med 1987;19:109 13 .

54 Leigh JP, Sheetz RM. Prevalence of back pain among fulltime United States workers. Br F Ind Med 1989;46:6517.

55 Park CH, Wagener DK, Winn DM, et al. Health conditions among the currently employed. Vital Health Stat 1993;186 $1-67$

56 Croft PR, Rigby AS. Socioeconomic influences on back problems in the community in Britain. $\mathcal{F}$ Epidemiol Coтmunity Health 1994;48:166-70.

57 Liira JP, Shannon HS, Chambers LW, et al. Long-term back problems and physical work exposures in the 1990 Ontario problems and physical work exposures in the 1990

58 Hurwitz E, Morgenstern A. Correlates of back problems and back-related disability in the United States. $\mathcal{F}$ Clin Epidemiol 1997;50:669-80.

59 Stronks K, Van De Mheen H, Van Den Bos J, et al. The interrelationship between income, health and employment status. Int f Epidemiol 1997;26:592-600.

60 Latza U, Kohlmann T, Deck R, et al. Influence of occupational factors on the relation between socioeconomic status and self-reported back pain in a populationbased sample of German adults with back pain. Spine 2000;25:1390-7.

61 Von Korff M, Le Resche L, Dworkin SF. First onset of common pain symptoms: a prospective study of depression as a mon pain symptoms: a prospective
risk factor. Pain 1993;55:251-8.

62 Harreby M, Kjer J, Hesselsøe G, et al. Epidemiological aspects and risk factors for low back pain in 38-year-old men and women: a 25-year prospective cohort study of 640 school children. Eur Spine f 1996;5:312-18.

63 Barnekow-Bergkvist M, Hedberg GE, Janlert U, et al. Determinants of self-reported neck-shoulder and low back symptoms in a general population. Spine 1998;23:235-43.

64 Jayson MIV. Why does acute back pain become chronic? BMF 1997;314:1639-41.

65 Magora A. Investigation of the relation between low back pain and occupation. IMS Ind Med Surg 1970;39:465-71.

66 Svensson H. Low back pain in forty to forty-seven year old men. II. Socio-economic factors and previous sickness absence. Scand f Rehab Med 1982;14:55-60.

67 Biering-Sørensen F, Thomsen C. Medical, social and occupational history as risk indicators for low-back trouble in a general population. Spine 1986;11:720-5.

68 Roncarati A, McMullen W. Correlates of low back pain in a general population sample: a multidisciplinary perspective. f Manipulative Physiol Ther 1988;11:158-64.

69 Armenian HK, Halabi SS, Khlat M. Epidemiology of primary health problems in Beirut. $\mathcal{F}$ Epidemiol Community Health 1989;43:315-18.

70 Bergenudd H, Nilsson B. Back pain in middle age; occupational workload and psychologic factors : An epidemiologic survey. Spine 1988;13:58-60.
71 Bergenudd H, Nilsson B. The prevalence of locomotor complaints in middle age and their relationship to health and socioeconomic factors. Clin Orthop 1994;308:264-70.

72 Rothman KJ, Greenland SE. Modern epidemiology. 2nd ed Philadelphia: Lippincott Williams and Wilkins, 1998.

73 Liberatos P, Link BG, Kelsey JL. The measurement of social class in epidemiology. Epidemiol Rev 1988;10:87-121

74 Von Korff M, Parker RD. The dynamics of the prevalence of chronic episodic disease. F Chron Dis 1980;33:79-85.

75 Deyo RA, Tsui-Wu YJ. Functional disability due to back pain. Arthritis Rheum 1987;30:1247-53.

76 Deyo RA, Diehl AK. Psychosocial predictors of disability in patients with low back pain. F Rheumatol 1988;15:1557-64. 7 Astrand NE, Isacsson SO. Back pain, back abnormalities, and competing medical, psychological, and social factors as predictors of sick leave, early retirement, unemployment, labour turnover and mortality: a 22 -year follow-up of male employees in a Swedish pulp and paper company. Br f Ind Med 1988;45:387-95.

78 Volinn E, Van Koevering D, Loeser J. Back sprain in industry: the role of socioeconomic factors in chronicity. Spine 1991;16:542-8.

79 Mäkelä M, Heliövaara M, Sievers K, et al. Musculoskeletal disorders as determinants of disability in Finns aged 30 years or more. f Clin Epidemiol 1993;46:549-59.

80 Von Korff M, Deyo RA, Cherkin D, et al. Back pain in primary care. Outcomes at 1 year. Spine 1993;18:855-62.

81 Badley EM, Ibañez D. Socioeconomic risk factors and musculoskeletal disability. F Rheumatol 1994;21:515-22.

82 Dionne C, Koepsell TD, Von Korff M, et al. Formal education and back-related disability: in search of an explanation. Spine 1995;20:2721-30.

83 Kearney JR. The work incapacity and reintegration study: results of the initial survey conducted in the United States. Soc Secur Bull 1997;60:21-32.

84 Magora A, Taustein I. An investigation of the problem of sick-leave in the patient suffering from low back pain. IMS Ind Med Surg 1969:38:398-408.

85 Westrin CG, Hirsch C, Lindegård $\mathrm{B}$. The personality of the back patient. Clin Orthop 1972;87:209-16.

86 Murphy KA, Cornish RD. Prediction of chronicity in acute low back pain. Arch Phys Med Rehabil 1984;65:334-7.

87 Lanier DC, Stockton P. Clinical predictors of outcome of acute episodes of low back pain. $\mathcal{F}$ Fam Pract 1988;27:4839.

88 Lee PWH, Chow SP, Lieh-Mak F, et al. Psychosocial factors influencing outcome in patients with low-back pain. Spine 1989;14:838-43.

89 Cats-Baril WL, Frymoyer JW. Identifying patients at risk of becoming disabled because of low-back pain. The Vermont Rehabilitation Engineering Center predictive model. Spine 1991;16:605-7.

90 Lancourt J, Kettelhut M. Predicting return to work for lower back pain patients receiving worker's compensation. Spine 1992;17:629-40.

91 Lehmann TR, Spratt KF, Lehmann KK. Predicting ong-term disability in low back injured workers presenting to a spine consultant. Spine 1993;18:1103-12.

92 Polatin PB, Gatchel RJ, Barnes D, et al. A psychosociomedical prediction model of response to treatment by chronically disabled workers with low-back pain. Spine 1989;14:956-61.

93 Nykvist F, Hurme M, Alaranta $\mathrm{H}$, et al. Social factors and outcome in a five year follow up study of 276 patients with sciatica. Scand F Rehabil Med 1991;23:19-26.

94 Natvig H. Sociomedical aspects of low back pain causing prolonged sick leave. Acta Socio-Med Scand 1970;2-3:117-

95 Wilfling FJ, Klonoff H, Kokan P. Psychological, demographic and orthopaedic factors associated with prediction Kokan PJ, Wing PC, Thompson WJ. Factors associated with Kokan PJ, Wing PC, Thompson WJ. Factors associated with
failure of lumbar spine fusion. Can f Surg 1974;17:294-8. failure of lumbar spine fusion. Can f Surg 1974;17:294-8.
Tunturi T, Pätiälä H. Social factors associated with

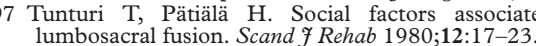

98 Oostdam EMM, Duivenvoorden HJ. Predictability of the result of surgical intervention in patients with low back pain. F Psychosom Res 1983;27:273-81.

99 Guck TP, Meilman PW, Skultety FM, et al. Prediction of

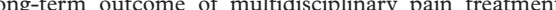
Arch Phys Med Rehabil 1986;67:293-6.

100 Alaranta H, Hurme M, Miettinen ML. Handicap 1 year following surgery for lumbar disc herniation: special reference to social and vocational factors. Int Rehabil Med 1986; 8:39-43.

101 Hurme M, Alaranta H. Factors predicting the result of surgery for lumbar intervertebral disk herniation. Spine 1987;12:933-8.

102 Kleinke CL, Spangler AS Jr. Predicting treatment outcome of chronic back pain patients in a multidisciplinary pain clinic: methodological issues and treatment implications. Pain 1988;33:41-8.

103 Fredrickson BE, Trief PM, VanBeveren P, et al. Rehabilitation of the patient with chronic back pain. A search for outcome predictors. Spine 1988;13:351-3.

104 Doxey NCS, Dzioba RB, Mitson GL, et al. Predictors of outcome in back surgery candidates. F Clin Psychol 1988;44:611-22.

105 Lacroix JM, Powell J, Lloyd GJ, et al. Low-back pain. Factors of value in predicting outcome. Spine 1990;15:495-9.

106 Hazard RG, Bendix A, Fenwick JW. Disability exaggeration as a predictor of functional restoration outcomes for patients with chronic low-back pain. Spine 1991;16:1062- 
107 Vucetic N, de Bri E, Svensson O. Clinical history in lumbar disc herniation. Acta Orthop Scand 1997;68:116-20.

108 Vucetic N, Astrand P, Guntner P, et al. Diagnosis and prognosis in lumbar disc herniation. Clin Orthop 1999;361: $116-22$.

109 Fishbain DA, Cutler RB, Rosomoff HL, et al. Impact of chronic pain patients' job perception variables on actual return to work. Clin f Pain 1997;13:197-206.

110 Keel PJ, Wittig R, Deutschmann R, et al. Effectiveness of in-patient rehabilitation for sub-chronic and chronic low back pain by an integrative group treatment program (Swiss Multicentre Study). Scand f Rehabil Med 1998;30: 211-19.

111 Kushi LH, Folsom AR, Jacobs DR, et al. Educational attainment and nutrient consumption patterns: the Minnesota Hearth Survey. $\mathcal{F}$ Am Diet Assoc 1988;88:1230-6.

112 Pierce JP, Fiore MC, Novotny TE, et al. Trends in cigarette smoking in the United States: Educational differences are increasing. $7 A M A 1989 ; 261: 56-60$.

113 Smith AM, Baghurst KI. Public health implications of dietary differences between social status and occupational category
$409-16$.

114 Woo J, Leung SS, Ho SC, et al. Influence of educational level and marital status on diatery intake, obesity and other cardiovascular risk factors in a Hong Kong Chinese population. Eur F Clin Nutr 1999;53:461-7.

115 Frymoyer JW, Pope MH, Costanza MC, et al. Epidemiologic studies of low-back pain. Spine 1980;5:419-23.

116 Ernst E. Smoking, a cause of back trouble? Br f Rheumatol 1993;32:239-42.

117 Leino P, Magni G. Depressive and distress symptoms as predictors of low back pain, neck-shoulder pain, and other musculoskeletal morbidity: a 10-year follow-up of metal industry employees. Pain 1993.53:89-94.

118 Harreby M, Hesselsøe G, Kjer J, et al. Low back pain and physical exercise in leisure time in 38-year-old men and women: a 25 -year prospective cohort study of 640 school women: a 25-year prospective cohort

119 Boshuizen HC, Verbeek JHAM, Broersen JPJ, et al. Do smokers get more back pain? Spine 1992;18:35-40.

120 Orvieto R, Rand N, Lev B, et al. Low back pain and body mass index. Mil Med 1994;159:37-8.

121 Leino P. Symptoms of stress predict musculoskeletal disorders. F Epidemiol Community Health 1989;43:293-300.

122 Pincus T, Callahan L. Associations of low formal education level and poor health status: behavioral, in addition to demographic and medical, explanations? F Clin Epidemiol 1994;47:355-61.

123 Pincus T, Brooks RH, Callahan LF. Prediction of long-term mortality in patients with rheumatoid arthritis according to simple questionnaire and joint count measures. Ann Intern Med 1994;120:26-34.

124 Pincus T, Callahan LF. What explains the association between socioeconomic status and health: primarily access to medical care or mind-body variables? Advances: The fournal of Mind-Body Health 1995;11:4-36.

125 Callahan LF, Cordray DS, Wells G, et al. Formal education and five-year mortality in rheumatoid arthritis: mediation by helplessness scale score. Arthritis Care Res 1996;9:46372 .

126 Callahan LF, Pincus T. Education, self-care, and outcomes of rheumatic diseases: further challenges to the "biological model" paradigm. Arthritis Care Res 1997;10:283-8.

127 Rowe ML. Low back pain in industry: a position paper. $f$ Occup Med 1969;11:161-9.

128 Svensson HO, Andersson GBJ. Low back pain in forty to forty-seven year old men. I. Frequency of occurrence and impact on medical services. Scand F Rehab Med 1982;14: 47-53.

129 Vallförs B. Acute, subacute and chronic low-back pain: clinical symptoms, absenteism and working environment. Scand F Rehabil Med 1985; suppl 11:1-98.

130 Institute of Medicine. Pain and disability: clinical, behavioral and public policy perspectives. Washington DC: National Academy Press, 1987.

131 Smith R, ORourke DF. Return to work after a first myocardial infarction: test of multiple hypotheses. $\mathcal{F A M A}$ 1988;259:1673-7.

132 Burdorf A. Exposure assessment of risk factors for disorders of the back in occupational epidemiology. Scand 7 Work Environ Health 1992;18:1-9.

133 Grossman M. The demand for health: a theoretical and empirical investigation. New York: National Bureau of Economic Research, 1972.

134 Blumer D, Heilbronn M. Chronic pain as a variant of depressive disease. $\mathcal{F}$ Nerv Mental Dis 1982;170:381-406.

135 Gentry WD, Shows WD, Thomas M. Chronic low back pain: a psychological profile. Psychosomatics 1974;15:1747.

136 Porter RW, Oakshot G. Spinal stenosis and health status. Spine 1994;19:901-3.

137 Pincus T, Esther R, DeWalt DA, et al. Social conditions and self-management are more powerful determinants of health than access to care. Ann Intern Med 1998;129:40611.

138 Cassel J. The contribution of the social environment to the host resistance. Am f Epidemiol 1976;104:107-23.

139 Henry JP, Cassel J. Psychosocial factors in essential hypertension: recent epidemiologic and animal experimental evidence. Am f Epidemiol 1969;90:171-200.

140 Melzack R, Wall PD. The challenge of pain. New York: Basic Books, 1983.

141 Kubzansky LD, Kawashi I, Sparrow D. Socioeconomic status, hostility, and risk factor clustering in the normative aging study: any help from the concept of allostatic load? Ann Behav Med 1999;21:330-8. 